\title{
O AMARGO ADEUS ÀS ARMAS: A TRÁGICA SAGA DOS SOLDADOS DA BORRACHA NA AMAZÔNIA ${ }^{1}$
}

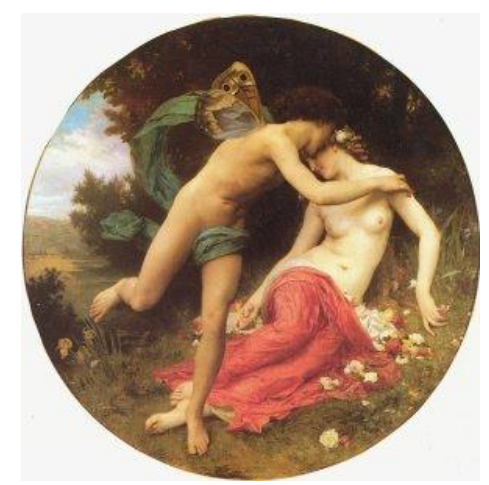

Sidney Barata de Aguiar ${ }^{2}$

\begin{abstract}
Resumo
$\mathrm{O}$ ataque surpresa contra a base naval americana de Pearl Harbor, abriu o caminho para o Japão conquistar o Sudeste Asiático e suas plantações de borracha na Malásia. Ocasionando uma enorme problemática para indústria bélica dos países aliados no combate ao III Reich na II Grande Guerra (1939-1945). Este episódio reaqueceria a economia gomífera da região amazônica e a criação de um aparato logístico-institucional celebrados pelos "Acordos de Washington". Novamente, a mão de obra nordestina, sob o epíteto de "soldados da borracha", chegam aos seringais da hinterlândia amazônica em nome do "esforço de guerra" defendido por Getúlio Vargas. Este artigo tem por objetivo principal abordar o abandono destes trabalhadores com o término da refrega internacional e o perceptível silêncio historiográfico sobre o tema.
\end{abstract}

Palavras-chave: Amazônia; II Guerra Mundial; Soldados da Borracha.

\begin{abstract}
The surprise attack against the American naval base of Pearl Harbor, paved the way for Japan to conquer Southeast Asia and rubber plantations in Malaysia. Causing a huge problem for military industry of the allied countries in the fight against the Third Reich in World War II (1939-1945). This episode heat again the rubber economy of the Amazon region and the creation of a logistical and institutional apparatus concluded by "Washington Agreement". Again, the northeastern labor under the epithet of "rubber soldiers", arrive at rubber plantations of Amazon land on behalf of the war effort
\end{abstract}

${ }^{1}$ Este trabalho faz parte da dissertação Arigós, Jabá e o Caso da Carne Verde: vivências populares na cidade de Manaus (1939-1949) defendida no âmbito do PPGH (Programa de Pós-Graduação em História) orientada pelo Prof. Dr. Marcos César Borges da Silveira.

2 Mestre em História Social pela Universidade Federal do Amazonas. aguiar_sidney@yahoo.com.br. 
championed by Getúlio Vargas. This article has as main objective to address the abandonment of these workers with the end of the melee and the noticeable international historiographical silence on the subject.

Keywords: Amazon; World War II; Rubber soldiers.

$$
\begin{array}{r}
\text { E foi por tua ponte flutuante } \\
\text { Que chegaram as "levas" nordestinas } \\
\text { Dos "brabos", dos "soldados da } \\
\text { borracha" } \\
\text { Que seguiam encantados, enganados, } \\
\text { Para os "centros" - distantes } \\
\text { seringais - } \\
\text { Do Purus, Acre, Madeira e Juruá } \\
\text { Onde findavam - finavam - } \\
\text { escravizados. }
\end{array}
$$

Os japoneses pretendiam montar uma nova ordem econômica e política na Ásia Oriental e para isto, a conquista das águas oceânicas do Extremo Oriente e do Pacífico Ocidental foi colocada em prática (FERRO, 1996, p. 129). No dia 07 de dezembro de 1941, a marinha imperial japonesa disparou toneladas de munição sobre a desavisada e sonolenta frota americana ancorada na base naval de Pearl Harbor, no arquipélago do Havaí, durante uma manhã de domingo. Este ataque mudou radicalmente a opinião de Franklin Delano Roosevelt, então presidente dos Estados Unidos da América, que até aquele momento, vinha defendendo uma política de neutralidade e não intervenção contra as hostilidades que se desenrolavam na Europa durante a Segunda Grande Guerra (1939-1945).

O Japão tomara posse do Sudeste Asiático e mais uma peça no teatro de guerra mundial foi movimentada. Desta forma, as forças armadas nipônicas controlaram mais de $90 \%$ das áreas produtoras de goma elástica no Pacífico (NETO, 2000, p. 33), além das plantações de arroz e zonas de

${ }^{3}$ Trecho do poema Crônica romântica de adeus ao Roadway do bardo L. Ruas in Manaus, meu sonho. / Organização: José Joaquim Marinho Marques. Manaus: editora Valer, Prefeitura de Manaus, ManausCult, 2010,pp. 53 - 57. 
mineração de estanho.

Esta tomada de posição estratégica colaborou com o ressurgimento ou reaquecimento da borracha silvestre na economia do Amazonas. Os países aliados (Estados Unidos, Inglaterra, França e URSS) necessitavam de enormes quantidades de látex da Hevea brasiliensis(Seringueira) para a indústria bélica ${ }^{4}$ para o enfrentamento armado contra as forças do Terceiro Reich.

Neste contexto, foram celebrados os "Acordos de Washington" que objetivava o "soerguimento da economia gomífera na Região Amazônica, haja vista que grande parte dos antigos seringais da região já haviam sido abandonados" (NETO, Op. Cit., p. 35).

Segundo Luiz de Miranda Corrêa (1965) a contenda internacional aqueceria a comercialização, as exportações da borracha e a montagem de uma infraestrutura com diversas empresas brasileiras, estadunidenses ou mistas, todas dedicadas a responder ao "esforço de guerra" em menor tempo possível. Em relação a obtenção de mão de obra, empreenderam o “alistamento"de centenas de nordestinos, oriundos de regiões castigadas pelos fenômenos da seca.

Aprocura daquimera do El Dorado na planície amazônica iniciava nos barracões do SEMTA (Serviço Especial de Mobilização de Trabalhadores para a Amazônia), que seria substituída pela CAETA (Comissão Administrativa do Encaminhamento de Trabalhadores para a Amazônia) (SECRETO, 2007a, p. 90) no Nordeste brasileiro, locais onde recebiam, sandálias alparcatas, roupas, canecas, pratos e talheres, mochila, chapéu, cigarros e uma rede para serem enviados para Belém e dali "subirem" o rio Amazonas para então, serem distribuídos pelos seringais nativos dos Estados do Pará, Rondônia, Acre e Amazonas, escrevendo mais um capítulo da saga da chamada "Batalha da Borracha".

4MENDES, Amando. A borracha no Brasil. São Paulo, dezembro de 1942. 
Começava assim, uma longa peregrinação, que passava pelo perigo do torpedeamento dos navios disparados pelos submarinos alemães, submersos no litoral brasileiro, falta de assistência médica, má alimentação, solidão na selva e até doenças de clima tropical como malária, febre amarela, béri-béri e icterícia.

Os "pousos" eram locais onde o SEMTA reunia os trabalhadores sertanejos que eram depois transportados para a Hospedaria de Tapanã em Belém e distribuídos nos seringais amazônicos. Havia "pousos" nas cidades cearenses de Fortaleza, Sobral, Iguatú, Tianguá, em São Luiz, Coroatá, Caxias, no Maranhão, em Teresina, capital do Piauí e Bragança, no Estado do Pará ${ }^{5}$.

A partir do momento em que eram acolhidos nos "pousos" do Nordeste, eram fornecidas aos trabalhadores no mínimo três refeições diárias: café da manhã, almoço e jantar. Apesar da iniciativa de diversificar o cardápio destes migrantes para combater a má alimentação e um grande número de enfermidades que acometiam estes homens, mulheres e crianças, houve uma grande resistência ao consumo de legumes e verduras, já que o hábito de preferir comer charque e farinha estava bastante arraigado e isto explicava a oposição de cunho alimentar ${ }^{6}$.

Antônio Luiz Macêdo Silva Filho (2008), afirma que na frente europeia, os riscos de doenças como a pneumonia, a inanição e as armas do inimigo estavam sempre presentes. Enquanto na frente amazônica além das enfermidades já citadas, também foram registrados a subnutrição e um pesado regime de trabalho.

Os "pracinhas", soldados da Força Expedicionária Brasileira (FEB),foram recebidos como heróis nacionais ao término do embate contra o nazi-fascismo. Em Manaus, as festividades iniciaram com a

${ }^{5}$ Relatório da Comissão Administrativa do Encaminhamento de Trabalhadores para a Amazônia (CAETA), dezembro de 1945.

${ }^{6}$ Relatório da CAETA, dezembro de 1945. 
chegada do Navio Cambridge ao Roadway, saindo em marcha pela Avenida Eduardo Ribeiro até a Catedral de Nossa Senhora da Conceição Padroeira do Amazonas - e depois seguiram para o quartel do $27^{\circ}$ Batalhão de Caçadores". Ao passo que, os "soldados da borracha", frequentemente "anônimos, desprovidos de patente e condecoração, trouxeram em seus corpos as marcas das penosas lidas, testemunhas do estreito convívio entre látex e sangue" ${ }^{\prime 8}$.

Navegando pelos cursos d'água dentro de "gaiolas"' do SNAPP (Serviço de Navegação da Amazônia e Portos do Pará), os sertanejos se embrenhavam na floresta dos mais distantes pontos da Amazônia em busca do trabalho extrativista e da produção das "pélas" de borracha nas suas respectivas "colocações". ${ }^{11}$

Abaixo, demonstro a identidade para embarque e colocação do seringueiro João Batista de Aguiar, natural de Crateús no Estado do Ceará, 55 anos de idade, agricultor. Além de trazer a informação do trajeto percorrido pelo trabalhador que ficou hospedado em Fortaleza e seguiu para o "pouso" de Tapanã na cidade de Belém. Quanto ao seu destino e colocação a indicação é a direção do Estado do Amazonas no Vapor Pará State, mais especificamente no Rio Invira e seu local de trabalho seria um seringal homônimo.

Com o intuito de tornar oficial a condição militar destes "soldados da borracha", o governo de Vargas criou, através do decreto-lei n. ${ }^{\circ}$ 5.225,

7O JORNAL, 14 de novembro de 1945, quarta-feira, ano XV.

${ }^{8}$ Estilhaços de uma guerra. Antônio Luiz Macêdo e Silva Filho.In Mais borracha para a Vitória/ Adelaide Gonçalves, Pedro Eymar Barbosa Costa (Organizadores). Fortaleza: MAUC/NUDOC; Brasília: Ideal Gráfica, 2008,p. 26. 9 Assim eram conhecidas as embarcações fluviais que serviam como meio de transporte para os migrantes e da população do interior.

${ }^{10}$ Bolas de borracha em estado bruto.

11 Seringais para onde eram encaminhados os "soldados da borracha" e em muitos casos acompanhados de seus dependentes. 
de $1^{\circ}$ de setembro de 1943, o chamado "Batalhão da Borracha"12.

Este "soldado da borracha" veio em companhia de esposa Maria Silveira, 42 anos e seis filhos menores de idade (Vicente, Manoel, Francisca, Ana, Raimundo e Francisco) em busca de um futuro mais promissor na cognominada "terra da fartura".

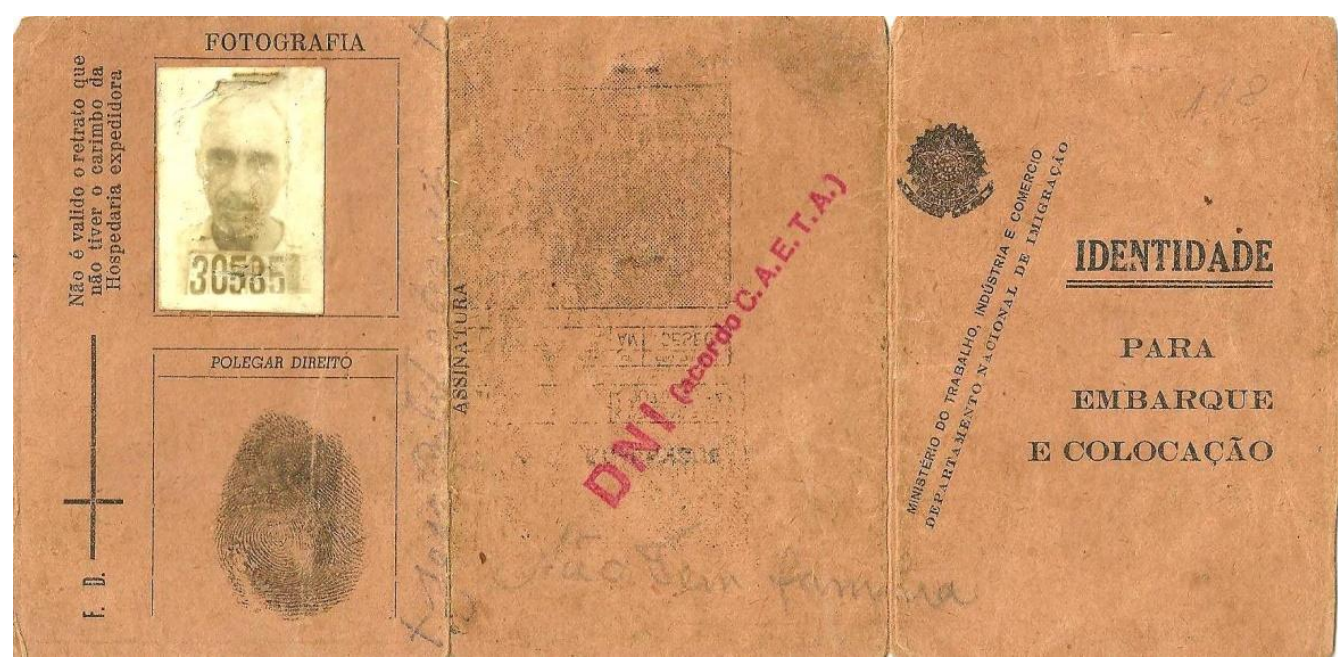

Figura 01: Identidade de embarque e colocação de seringueiros (Frente).

Fonte: Arquivo particular de Sidney Barata de Aguiar.

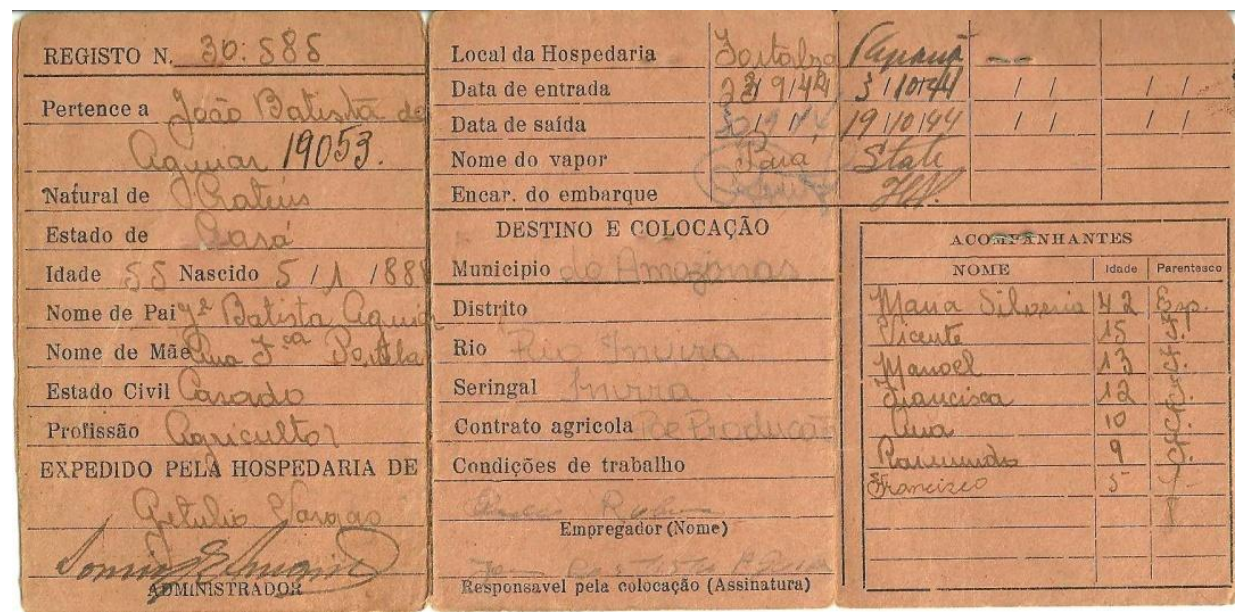

${ }^{12}$ MATIAS, Francisco. Pioneiros: ocupação humana e trajetória política de Rondônia. Gráfica e Editora Maia Ltda. Porto Velho, 1997, p. 86. 
Figura 02: Identidade de embarque e colocação de seringueiros (Verso).

Fonte: Arquivo particular de Sidney Barata de Aguiar.

Os discursos de Getúlio Vargas, que capitaneava o Estado Novo (1937-1945) em vigor, fomentavam, significativamente, a ideia de integrar a região Norte ao restante do país e também o desenvolvimento da Amazônia como área estratégica do Brasil (SECRETO, 2007b). A reativação da economia amazônica, sob o aspecto extrativo da borracha e dentro do contexto/ do chamado "esforço de guerra" é destacada por Carlos Mendonça (2002) que considerava, tal feito, como uma das mais importantes ações realizadas do governo brasileiro. Mendonça reproduz a fala de Donald Nelson, Diretor Geral da indústria bélica americana em reunião com alguns líderes na Casa Branca (Washington D.C.) exclamara com convicção: "Sem borracha talvez ganhemos a guerra; com a borracha ganhá-la-emos seguramente” (MENDONÇA, Op. Cit., p. 37).

Carlos Mendonça que esteve em Manaus para acompanhar a chegada de levas migratórias de nordestinos para o Lago do Aleixo, onde o Interventor Federal Álvaro Maia ${ }^{13}$ havia inaugurado um "pouso" para os viajantes, não deixou passar despercebida, a situação deplorável destes brasileiros e brasileiras.Assim ele descreveu:

Os velhos chegam taciturnos e sombrios, relembrados da terra sertaneja, que não verão jamais. Os jovens espalham-se pela praça, admirados de encontrar no seio escuro da Selva tantas casas novas, amplas, confortáveis. Mulheres gritam e gesticulam á procura das bagagens, com os filhos agarrados ao colo. As

13 Álvaro Botelho Maia nasceu em 19 de fevereiro de 1893 na cidade de Humaitá (AM) e comandou o Amazonas durante três períodos (1930 - 1931 / 1935 -1945 / 1951 - 1954). 
fisionomias são profundamente abatidas, todas. Roupas sórdidas. Descalços (Op. Cit., p. 06).

Apesar das instalações apresentarem boa qualidade havia sempre o problema de adaptação. E ainda compara:

Não são tropas de invasão; não são prisioneiros de guerra. São os prisioneiros da fome - os nordestinos libertados do círculo de chamas dos sertões requeimados. Cerca de 2 mil pessôas - homens, creanças, mulheres - desembarcam dos caminhões. Com a mais variada bagagem. Caixas, malas, sacos, violões, armónicas, bacias, fogareiros, baús de sóla, pacotes, embrulho - toda a fardagem e uma grande massa em retirada (...)(2002, p. 05).

A alegria da saída de Fortaleza em direção às regiões de extração, rapidamente era substituída pelos percalços de uma longa e cansativa jornada. Esses trabalhadores enfrentariam o calor amazônico, suas peculiaridades naturais e não conseguiriam alcançar o objetivo de aumentar a produção da borracha, como determinava os governos brasileiro e americano.

O jornalista Edgar Morel, percorrendo a região amazônica, também deixou registradas suas impressões sobre as péssimas condições de saúde e total abandono deste verdadeiro "exército da borracha". Segundo suas linhas, o observador deparou-se em Manaus e na cidade de Belém com:

[...] apenas molambos de gente atirados no fundo das hospedarias, todos impaludados, famintos e sem um nickel no bolso, esperando que o governo conceda a passagem de regresso. [...] Ei-los famintos e rôtos implorando a caridade publica nas cidades da Amazonia. Outros, mais desgraçados, levados pela 
fome, cumprem pena nas cadeias, por crime de roubo e furto. ${ }^{14}$

Centenas de "soldados da borracha" abandonados, desassistidos e sem condiçõesmínimas de sobrevivência ficaram impossibilitados de retornar aos seus torrões de origem, assim fixando residências ao longo das calhas dos rios ou caminhando famélicos para as principais cidades da Região Norte. Transformavam-se nos verdadeiros deserdados do látex.

Muitos nordestinos não foram avisados do término da refrega na Europa e continuaram trabalhando pesado nos seringais. Como pagamento pelos serviços patrióticos receberam o descaso do governo, a saúde debilitada e a extrema pobreza.

Samuel Benchimol(1992) foi testemunha ocular da falta de ajuda financeira para estes trabalhadores que o autor chama de "filhos pródigos da borracha e da fortuna".Segundo ele, estes pobres:

(...) abandonavam os seringais endividados e rumavam para as cidades de Rio Branco, Porto Velho, Manaus, Santarém, Belém, onde se afavelavam, ou para os pequenos vilarejos e cidades do interior para recomeçarem a luta da vida (1992, P. 228).

Nesta peregrinação jornalística, Morel teve a oportunidade de entrevistar o Sr. Auton Furtado, então presidente da Associação dos Seringalistas do Amazonas. Nas palavras do leader, o repórter teve contato com "apenas alguns casos esporádicos" e que os "bons trabalhadores" continuavam dispostos para o trabalho árduo de extração do látex. O seringalista ressaltou que estes trabalhadores estavam sempre "ombro a ombro com seus chefes". Observem que estes seringueiros que não se adaptavam ao serviço ou por discordarem de algum ponto desta relação

${ }^{14}$ O JORNAL, 27 de setembro de 1949, terça-feira, ano XVIII. 
trabalhista não escapavam da pecha de preguiçoso, indolente e mau trabalhador. ${ }^{15}$

Alguns migrantes, já no ano de 1943, ouvindo as notícias das péssimas condições de vida e trabalho nos seringais desistiam de continuar o trajeto e preferiam ficar nas cidades,criando de certa forma, um novo estereotipo de imigrante facilmente reconhecido ao desembarcar nas principais cidades do Norte, principalmente pela:

[...] maneira desajeitada, "quando pelas ruas caminhava". A vivência da floresta, o fez habituado a andar, sempre um atrás do outro, ou seja, "em fila". Essa prática de caminhar em filas, mesmo quando se encontrava na cidade, era motivo de chacotas" (MEDEIROS, 2004, p. 103).

Apesar da zombaria estes "arigós" comumente eram vistos trajando roupas de fazenda barata, típico destes "soldados da borracha" e sempre portando a "peixeira" ao lado, como símbolo da valentia nordestina. Vestiam-se com:

[...] calça frouxa de mescla, chapéu de palha virado, blusa larga de algodão, mochila às costas, alpercata de rabicho, barba grande, a "peixeira" à ilharga. Andavam aos bandos à procura de emprego, de estância para morar, da petisqueira e da birosca para comer a sua "gororoba", do boteco para beber a "maldita" e esquecer os mal-ditos, e das festas e dos "arrasta-pés" dos bairros pobres, onde iam à procura de diversão; não raro, transformavam-nas em cenas de bebedeiras, de valentias e de "pega-prá-capar" (BENCHIMOL, 1992, p. 229).

Charles Wagley(1998) ressalta que,todos os investimentos monetários, não foram suficientes para evitar o fracasso do programa de desenvolvimento da borracha, segundo o autor "a produção da borracha da

15 O JORNAL, 27 de setembro de 1949, terça-feira, ano XVIII. 
Amazônia brasileira que era de cerca de 19.000 toneladas em 1940, em 1944 havia aumentado para apenas cerca de 25.000 toneladas"16. Havia também, os aspectos geográficos, sociológicos e culturais, detectados pelo pesquisador americano que apontou algumas causas, como a indústria de borracha bruta depender das árvores de seringa e estas ficarem distantes uma das outras, responsáveis pela exaustão do trabalhador empregado nofatiganteexercício de coleta do látex. Igualmente, no processo de abertura de novas estradas ou da reabertura das antigas é necessário um mínimo de conhecimento da topografia do terreno, desta forma, os "arigósbrabos" desconheciam tais técnicas dificultando sobremaneira a produção.

Aqui o termo "arigó brabo", refere-se aos imigrantes nordestinos que ainda não haviam acostumado com o viver na floresta e apresentavam uma produção muito pequena nos primeiros anos de atividade, e claro, por outro lado, o "arigó manso" era aquele sujeito que já tinha se ambientado com as peculiaridades da Amazônia ${ }^{17}$.

Além do mais, ainda no rastro deixado por Charles Wagley:

O tempo era escasso e os técnicos e administradores do Sul do Brasil e do estrangeiro não compreendiam a sociedade amazônica. Desconheciam os incentivos próprios a estimular a população rural do Amazonas a despender maiores esforços e não compreenderam a força tradicional do sistema comercial da Amazônia, que consideravam muito diferente e explorador e,

16 Reforçando este raciocínio temos os dados disponibilizados por Samuel Benchimol em seu Romanceiro da Batalha da Borracha (Op. Cit.) que tratam da exportação de borracha silvestre para o exterior, temos os seguintes números em toneladas no quinquênio 1940-1945 respectivamente: 11.835, 10.734, 12.204, $14.575,21.192$ e 18.887. Verificar tabela encontrada na página 118 desta obra. Demonstrando que as expectativas foram ainda menores para o que era proposto e pretendido.

17Uma discussão sobre as várias versões do termo "arigó" está em BENCHIMOL. Op. Cit.,pp. 236-254. 
portanto, uma barreira à grande produção da borracha (Op. Cit., p. 74).

Estes interesses representados por programas diferenciados também são demonstrados por Cosme Ferreira Filho (1965), segundo ele:

O que, no entanto, não nos parece possível é satisfazer aos dois programas que se distanciam por sua natureza através dos mesmos processos de planificação e de realização. O programa brasileiro requer prudência, estudo, demorada imobilização das capitais, objetivando extensa e profunda transformação do sistema econômico em que se baseia a nossa produção gomífera. O outro - americano - implica rapidez de ação, aproveitamento e ampliação imediata de todos os recursos existentes, intensidade de trabalho e ritmo crescente, sob fórmulas que não se afastam muito do habitual desenvolvimento das operações de natureza militar, cujos frutos devem ser abundantes e prontos. $\mathrm{O}$ que ambiciona o govêrno brasileiro é, sem desestimar os lucros imediatos que a maior exportação da borracha proporciona ao país, a organização, em bases científicas, da nossa produção gomífera, como vigamestra da economia amazônica. O que pretende o governo americano é, pura e simplesmente, conseguir, dentro do mais breve espaço de tempo, o mais alto volume de borracha que se possa alcançar (1965, pp.128-129).

Barbara Weinstein (1993) debatendo a relação entre seringueiros e comerciantes no período que compreende a expansão e a decadência da borracha na Amazônia (1850 - 1920), relata que o sistema de comercialização prevalecente era conhecido como aviamento. $\mathrm{O}$ aviamento era um sistema baseado em uma rede de créditos e endividamento que iniciava com o seringueiro, passava pela figura do patrão, passava pela casa aviadora e esta pelas casas exportadoras que estavam ligadas as companhias compradoras de Nova York, Liverpool ou Londres ${ }^{18}$. Este sistema de

18 Sem citar os importadores e os banqueiros. 
trabalho mostrou-se "extremamente rígido e desumano" (PINHEIRO, 2011, p. 08).

Neste incomum complexo de comércio que permaneceu vivo nos seringais da década de 1940, é evidente que os trabalhadores nesta posição mais baixa desse "mastro totêmico" são os que mais sofriam todo tipo de agruras (WEINSTEIN, Op. Cit., 1993).

A alimentação e outros produtos eram comprados no barracão ou direto das mãos dos regatões ${ }^{19}$, prendendo o trabalhador a dívidas exorbitantes. As caçadas, segundo os seringalistas ${ }^{20}$, retiravam o tempo de trabalho na borracha, desta forma não estaria correspondendo ao apelo da pátria de maior produção.

A relação patrão-cliente estabelecida, impedia que o seringueiro rompesse com este tipo de mecanismo de dívidas pesadas e intermináveis ${ }^{21}$ no "barracão",22, representadas pelas anotações no "borrador" 23 .

Com o término do combate na Europa, essa massa de migrantes, acometidos por doenças da região, desamparados e descrentes de um futuro melhor nos seringais acabava seguindo o destino das cidades de Belém, Porto Velho, Rio Branco e Manaus como alternativa de salvação, de sobrevivência e, como consequência, "muitos se marginalizavam logo, outros desafogavam o desespero no crime, na valentia e na cachaça; as

19 Comerciantes que utilizavam de barcos regionais para comercializar todo tipo de mercadorias nos rios da Amazônia. Na maioria das trocava os produtos industrializados por produtos da floresta e revendiam em nas cidades.

${ }^{20}$ Proprietários dos seringais.

21Para mais informações indico o trabalho de TEIXEIRA, Carlos Corrêa. Servidão Humana na Selva - O aviamento e o barracão nos seringais da Amazônia. Manaus: Editora Valer/Edua, 2009.

22 Sede administrativa do seringal e onde os seringueiros adquiriam víveres e suprimentos.

23 O livro onde eram anotados os débitos e o quaseimpossível saldo do seringueiro. 
crônicas policiais da época registravam essas ocorrências nos jornais da cidade"(BENCHIMOL, 1992, p. 228).

A entrada destes "arigós" irá marcar um novo crescimento demográfico da cidade de Manausdecorrente do arrefecimento da extração da borracha. A repercussão deste processo migratórioensejou um amplo debate, no que consiste principalmente, o retorno dos seringueiros para suas localidades de origem.

O articulista Carlos de Avelar assina um artigo intitulado Festa Acabada, na qual deixa claro, sua indignação a cerca do valor de mercado pago pela goma elástica. Observem:

Borracha a um preço ridículo como este (12 centavos por libra) e os gêneros de primeira necessidade ultrapassando em preços as alturas dos picos andinos será um "verdadeiro maná de miséria para nós"... Mas a verdade é que a festa terminou... Nós fomos, apenas, os músicos... e a festa acabou. "Festa acabada, músicos a ponta pés..." 24

Outra discussão, bastante acalorada, orbitava sobre o destino deste verdadeiro exército de "soldados da borracha" abandonados à própria sorte e na "mais sórdida estagnação" econômica. Por isso, comumente ouvia-se brados no sentido de apontar soluções e alternativas políticas para o retorno a suas terras natais, como assina Kideniro Teixeira:

[...] Fazer regressar aqueles que aqui chegaram iludidos e aloujados como reses, no sonho luminoso de que encontrariam o El-Dorado da lenda secular [...] mas, regressem os miseráveis "soldados da borracha", aqueles que não tiveram festejos, clarins, bandeirinhas, discursos, passeatas e nem as solicitudaes hospitalares a se refletir numa dose de quinino! Os "soldados da borracha", país da saudosa e gorda SAVA- ninho de milhafre-mor do Amazonas, vindos aqui mais por um

24 O JORNAL, 26 de março de 1946, terça-feira, nº 6.553, ano XVI. 
dever patriótico que pela fome, que voltem aos seus pagos esses miseráveis, senhores líderes nordestinos! ${ }^{25}$

Essas vozes faziam coro a um discurso muito duro sobre esses “miseráveis", discussão que ecoava na capital do país, naquele momento, o Rio de Janeiro. Na verdade ninguém mais se responsabilizava em pagar a conta do transporte desses homens e mulheres de regresso para seus locais de origem. Assim temos que:

Notícias chegam do país sobre os homens do norte. Fala-se nos seringueiros sofredores, habitantes deste vale malsinado, que vieram para os prélios da campanha da borracha [...] Há quem diga também que esse seringueiro tristonho, triste pária nordestino que aportou por aqui, veio sonhando com a visão mirifica do "El Dorado", que as lábias instruídas de algum corredor de gado humano souberam plantar nos seus espíritos [...] O sol causticante e as águas avassaladoras não tiveram piedade dessa gente para balsamizar-lhe as dôres $[\ldots]^{26}$

Esse processo de esquecimento e abandono dos "soldados da borracha" terá um ponto final da responsabilidade dos americanos em 30 de julho 1947.

A parca literatura e os inéditos esforços acadêmicos, que insistem em priorizar est temática, nos mostra que, infelizmente, nem a força da natureza amazônica, nem a ganância humana tiveram piedade destes tristes párias nordestinos.

\section{Considerações Finais}

Com o fim do conflito armado mundial e a assinatura do armistício entre americanos e japoneses em 1945 foi gradativo e inevitável o

${ }^{25}$ O JORNAL, 26 de março de 1946, terça-feira, $n^{\circ}$ 6.553, ano XVI.

${ }^{26}$ O JORNAL, 21 de junho de 1946, sexta-feira, $\mathrm{n}^{\circ}$ 6.624, ano XVI.

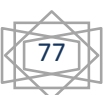


enfraquecimento e posteriormente, a total extinção dos "Acordos de Washington".

A vitória dos países aliados trouxe a recuperação e o domínio das áreas coloniais do Sudeste Asiático. E esta região prontamente, retorna ao posto de grande produtora mundial do "leite da seringueira".

A Rússia depois de adentrar as portas de Berlim na Alemanha também investe pesado na recuperação de sua indústria e a borracha sintética tem um papel imensurável para a reconstrução de sua economia.

Quanto ao caso brasileiro e especificamente a Amazônia,há sinais decrescimento de excedentes do látex durante alguns anos.No entanto, não havendo uma absorção da borracha pelo mercado consumidor interno e o cerceamento de créditos para a produção nos seringais foi gradativo o estrangulamento de uma economia, que já apresentava fragilidades.

Os dirigentes norte-americanos fecharam definitivamente "as torneiras" de investimentos na Amazônia em 30 de julho de 1947, inaugurando mais um capítulo cinzento da história em terras amazonenses.

A látex da borracha que novamente escorrega por nossos dedos, deixa para trás um rastro de estagnação econômica e letargia social. O Estado do Amazonas e a cidade de Manaus retornam ao estágio de esquecimento que já viveram no início do século XX. Passando a sobreviver com a extração da castanha do Brasil, juta, madeiras, especiarias e outros produtos extrativistas oriundos da floresta.

O colapso econômico foi tão brutal, que a economia do Estado do Amazonas, só retornou a ter um verdadeiro fôlego com a implantação da Zona Franca e o Polo Industrial de Manaus no final da década de 1960. Trazendo consigo as invasões e os problemas característicos sentidos pela Metrópole dos Manaós nos dias atuais.

Quanto aos "soldados da borracha" e suas famílias, somente na elaboração da Constituição Brasileira de 1988, foram parcialmente, reconhecidos pelos seus esforços e o direito a receber uma modesta 
aposentadoria de dois salários mínimos. Pior que sobreviver com esta injusta situação financeira, é ter que continuar o combate, desta vez, no front do esquecimento da história da Amazônia e do Brasil.

\section{Referências}

BENCHIMOL, Samuel. Romanceiro da Batalha da Borracha. Manaus: Imprensa Oficial, 1982.

CORRÊA, Luiz de Miranda. A Borracha do Amazonas e a Segunda Guerra Mundial. Manaus. Edições Governo do Estado, 1965.

FERREIRA FILHO, Cosme (1952). A Borracha na Economia Amazonense. In: Porque perdemos a batalha da Borracha. Manaus: Edições Gov. do Amazonas, série Euclides da Cunha (3) /Ed. Sergio Cardoso (1965).

FERRO, Marc. História das colonizações: das conquistas às independências, séculos XIII a XX; tradução Rosa Freire d'Aguiar. - São Paulo: Companhia das Letras, 1996.

FILHO, Antônio Luiz Macêdo e Silva. Estilhaços de uma Guerra. In: Mais Borracha para a Vitória/Adelaide Gonçalves, Pedro Eymar Barbosa Costa (organizadores). Fortaleza: MAUC/NUDOC; Brasília: Ideal Gráfica, 2008.

MARINHO, José Joaquim Marques. Manaus, meu sonho. / Organizador José Joaquim Marques Marinho. - Manaus: Editora Valer, Prefeitura de Manaus, ManausCult, 2010.

MATIAS, Francisco. Pioneiros: Ocupação humana e trajetória política de Rondônia. Francisco Matias. Gráfica e Editora Maia Ltda. Porto Velho, 1997.

MEDEIROS, Edilson Lucas de. A História da Evolução sociopolitica de Rondônia - $1^{\mathrm{a}}$ ed. Rondoforms Editora e Gráfica Ltda. Porto Velho - RO, 2004.

MENDES, Amando. A borracha no Brasil. São Paulo, dezembro de 1942.

MENDONÇA, Carlos. Gente do Nordeste no Amazonas. Manaus: Edições Governo do Estado do Amazonas/ Secretaria de Estado da Cultura, Turismo e Desporto, 2002. 
NETO, José Maria Bezerra. A economia da borracha e o esforço de guerra: Os Soldados da Borracha na Amazônia. In: Pontos de História da Amazônia, volume II / Armando Alves Filho, José Alves de Souza Júnior, José Maria Bezerra neto. - $2^{\circ}$ edição ampliada, - Belém: Paka-Tatu, 2000.

PINHEIRO, Maria Luiza Ugarte Pinheiro. Vivências Urbanas: o cotidiano de trabalhadores na contramão dos processos de modernização em Manaus. In: Fronteiras do Tempo: Revista de Estudos Amazônicos, v. 1, nº 2 - Dezembro de 2011.

SECRETO, María Verónica. Soldados da borracha: trabalhadores entre o sertão e a Amazônia no governo Vargas. São Paulo: Editora Fundação Perseu Abramo, 2007a.

SECRETO, María Verónica. A ocupação dos "espaços vazios" no governo V argas: do Discurso do rio Amazonas" à saga dos soldados da borracha. In: Estudos Históricos, Rio de Janeiro, n 40, julho-dezembro de 2007b.

TEIXEIRA, Carlos Corrêa. Servidão Humana na Selva - O aviamento e o barracão nos seringais da Amąônia. Manaus: Editora Valer/Edua, 2009.

WAGLEY, Charles. Uma Comunidade Amazônica: estudo do homem nos trópicos.

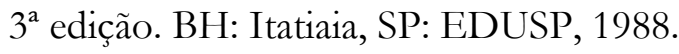

WEINSTEIN, Barbara. A borracha na Amazônia: expansão e decadência, 1850 1920; tradução Lólio Lourenço de Oliveira. - São Paulo: HUCITEC: Editora da Universidade de São Paulo, 1993.

\section{Fontes}

\section{A - PERIÓDICOS}

O JORNAL, 14 de novembro de 1945, quarta-feira, ano XV.

O JORNAL, 26 de março de 1946, terça-feira, n 6.553, ano VXI.

O JORNAL, 21 de junho de 1946, sexta-feira, ano, 6.624, ano XVI.

O JORNAL, 27 de setembro de 1949, terça-feira, ano XVIII.

\section{C - OUTRAS FONTES}

Relatório da Comissão Administrativo de Encaminhamento de Trabalhadores para a Amazônia (CAETA). Dezembro de 1945.

Identidade para Embarque e Colocação. Ministério do Trabalho, Indústria e Comércio (Departamento Nacional de Imigração). 